\title{
EFFECTS OF $\mathbf{R}_{\mathbf{P}}$ AND $\mathbf{S}_{\mathbf{P}}$ DIASTEREOISOMERS OF ADENOSINE 5'-O-(1-THIODIPHOSPHATE) ON HUMAN PLATELETS
}

\author{
N.J. CUSACK \& S.M.O. HOURANI \\ Department of Pharmacology, University of London King's College, Strand, London WC2R 2LS
}

$1 \quad \mathbf{R}_{\mathrm{P}}$ and $\mathbf{S}_{\mathrm{P}}$ diastereoisomers of adenosine 5'-O-(1-thiodiphosphate) ((R)-ADP- $\alpha$-S and (S)-ADP$\alpha$-S), an adenosine $5^{\prime}$-diphosphate (ADP) analogue, were tested on intact human platelets.

2 Each diastereoisomer induced aggregation, (S)-ADP- $\alpha$-S being 5 times more potent than (R)ADP- $\alpha$-S but they achieved only $75 \%$ of the maximal effect of ADP.

3 Aggregation induced by each diastereoisomer was competitively inhibited by ATP (50 $\mu \mathrm{M})$.

4 Simultaneous addition of each diastereoisomer inhibited aggregation induced by ADP but not by $11 \alpha, 9 \alpha$-epoxymethano prostaglandin $\mathrm{H}_{2}$, a stable endoperoxide analogue. Both diastereoisomers are therefore partial agonists at the ADP receptor mediating aggregation.

5 Unlike ADP, neither diastereoisomer inhibited prostaglandin $\mathrm{E}_{1}\left(\mathrm{PGE}_{1}\right)$-stimulated adenylate cyclase, but each competitively inhibited the effect of ADP, with (S)-ADP- $\alpha$-S again being 5 times more potent than (R)-ADP- $\alpha$-S.

6 These are the first reported examples of ADP analogues to induce platelet aggregation without inhibiting $\mathrm{PGE}_{1}$-stimulated adenylate cyclase.

\section{Introduction}

Adenosine $5^{\prime}$-diphosphate (ADP) is a physiologically important inducer of human platelet aggregation (Gaarder, Jonsen, Laland, Hellem \& Owren, 1961) and also causes non-competitive inhibition of prostaglandin $\mathrm{E}_{1}\left(\mathrm{PGE}_{1}\right)$-stimulated adenylate cyclase (Haslam, 1973). Some C'-substituted analogues of ADP have been shown to retain both these actions on human platelets (Macfarlane \& Mills, 1977; Macfarlane, Srivastava \& Mills, 1979). These actions of ADP are stereospecific in that its L-enantiomer, in which the D-ribofuranosyl moiety is replaced by L-ribofuranosyl, is completely inactive (Cusack, Hickman \& Born, 1979).

Adenosine 5'-O-(1-thiodiphosphate) (ADP- $\alpha$-S), an ADP analogue in which a non-terminal $(\alpha)$ phosphate oxygen (non-bridging) is replaced by sulphur, has an additional chiral centre at the $\alpha$ phosphate. unlike ADP. ADP- $\alpha$-S therefore exists as two diastereoisomers, $\left(\mathbf{R}_{\mathrm{P}}\right)$-adenosine 5'-O-(1-thiodiphosphate) ((R)-ADP- $\alpha-S)$ and $\left(\mathbf{S}_{\mathrm{P}}\right)$-adenosine $5^{\prime}-\mathrm{O}$ (1-thiodiphosphate) ((S)-ADP- $\alpha$-S), which are not mirror images (enantiomers) because they both contain the D-ribofuranosyl moiety (Eckstein \& Goody. 1976). To examine further the stereoselectivity for aggregation and for inhibition of $\mathrm{PGE}_{1}$-stimulated adenylate cyclase, we investigated the effects of $\mathbf{R}_{\mathbf{P}}$ and $\mathbf{S}_{\mathrm{P}}$ diastereoisomers of ADP- $\alpha-S$ on human platelets.

\section{Methods}

Human platelet-rich plasma (PRP) was obtained by centrifuging citrated venous blood at $260 \mathrm{~g}$ for $20 \mathrm{~min}$ and collecting the supernatant. Aggregation was quantified photometrically (Michal \& Born, 1971) as the maximal rate of change in light transmission (arbitrary units/min) through a $0.5 \mathrm{ml}$ sample of stirred PRP at $37^{\circ} \mathrm{C}$ on addition of test solutions.

To measure changes in levels of adenosine $3^{\prime}, 5^{\prime}$ cyclic monophosphate (cyclic AMP), PRP was preincubated with purified $\left[{ }^{14} \mathrm{C}\right]$-adenine to label platelet adenine nucleotides. After incubation with test solutions (containing papaverine to inhibit phosphodiesterase) for $20 \mathrm{~s}$ at $37^{\circ} \mathrm{C},\left[{ }^{14} \mathrm{C}\right]$-cyclic AMP was extracted, purified and estimated by liquid scintillation counting (Haslam \& Rosson, 1975). Measurements of the stimulation of $\left[{ }^{14} \mathrm{C}\right]$-cyclic AMP formation by $\operatorname{PGE}_{1}(1 \mu \mathrm{M})$ were carried out in the presence and absence of the nucleotides, and \% inhibition was calculated from the difference between these values after correction for the baseline effect of papaverine (2 mм) alone (Cusack \& Hourani, 1981).

ATP, ADP, papaverine hydrochloride, pyruvate kinase (E.C. 2.7.1.40) and creatine kinase (E.C. 2.7.3.2) were obtained from Sigma London. PGE and $11 \alpha, 9 \alpha$-epoxymethano prostaglandin $\mathrm{H}_{2}(11,9$ epoxymethano $\mathrm{PGH}_{2}$ ) were generous gifts from $\mathrm{Dr}$ J. Pike of the Upjohn Company in Kalamazoo, Michigan. $\left[\mathrm{U}-{ }^{14} \mathrm{C}\right]$-adenine was obtained from the 
Radiochemical Centre, Amersham. Adenosine 5'monophosphorothioate (AMPS) was obtained from Boehringer Mannheim. ADP- $\alpha$-S was synthesized by phosphorylation of AMPS (Eckstein \& Goody, 1976), and the two diastereoisomers obtained were separated by high performance liquid chromatography (h.p.l.c.) initially on an ion exchange column (Partisil 10-SAX, Whatman Ltd.) (after Stahl, Schlimme \& Bojanowski, 1973). Subsequently, and much more easily, they were separated by isocratic $\left(0.05 \mathrm{M} \mathrm{NH}_{4} \mathrm{H}_{2} \mathrm{PO}_{4}\right.$, $2 \mathrm{ml} / \mathrm{min}$ ) h.p.l.c. on a reverse phase column ( $\mu$ Bondapak C18, Waters Associates), and the $\mathbf{S}_{\mathrm{P}}$ configuration of the first eluted diastereoisomer (retention time $6 \mathrm{~min}$ ) and the $\mathbf{R}_{\mathbf{P}}$ configuration of the second eluted diastereoisomer (retention time $9 \mathrm{~min}$ ) were established by their selective phosphorylation by pyruvate kinase and creatine kinase respectively (Eckstein \& Goody, 1976; Burgers \& Eckstein. 1978).

\section{Results}

(R)-ADP- $\alpha$-S and (S)-ADP- $\alpha$-S induced platelet aggregation, but were less potent than ADP and achieved only about $75 \%$ of the maximal effect of ADP even at $400 \mu \mathrm{m}$. (S)-ADP- $\alpha$-S was about 5 times more potent than (R)-ADP- $\alpha$-S, and their approximate $\mathrm{EC}_{50}$ values taken from the log dose-response curves were $4 \mu \mathrm{M}$ and $20 \mu \mathrm{m}$ respectively (Figure la). Aggregation induced by (R)-ADP- $\alpha$-S or (S)-ADP$\alpha$-S was competitively inhibited by simultaneous addition of ATP $(50 \mu \mathrm{M})$ with an inhibitor constant ( $K_{\mathrm{i}}$ ) of about $33 \mu \mathrm{m}$ in both cases (Figure 1b). The $K_{\mathrm{i}}$ of ATP for the inhibition of ADP-induced aggregation was about $25 \mu \mathrm{M}$.

Aggregation induced by ADP was inhibited by simultaneous addition of (R)-ADP- $\alpha$-S $(200 \mu \mathrm{M})$ or (S)-ADP- $\alpha$-S $(200 \mu \mathrm{M})$. For example, aggregation induced by $5 \mu \mathrm{M}$ ADP alone was $20.6 \pm 1.1 \mathrm{units} / \mathrm{min}$, whereas it was reduced in the presence of $(\mathbf{R})$-ADP$\alpha$-S to $17.0 \pm 0.5$ units $/ \mathrm{min}$ and in the presence of (S)-ADP- $\alpha$-S to $17.1 \pm 0.9$ units/min (Figure 1c). Aggregation induced by 11,9-epoxymethano $\mathrm{PGH}_{2}$ was not inhibited by the simultaneous addition of (R)-ADP- $\alpha$-S $(200 \mu \mathrm{M})$ or (S)-ADP- $\alpha$-S (200 $\mu \mathrm{M})$ (Figure 1d).

Neither (R)-ADP- $\alpha$-S nor (S)-ADP- $\alpha$-S caused inhibition of $\mathrm{PGE}_{1}$-stimulated adenylate cyclase, even at $200 \mu_{\mathrm{M}}$ (Figure 1e). The inhibition by ADP of $\mathrm{PGE}_{1}$-stimulated adenylate cyclase was competitively inhibited by the simultaneous addition of $(\mathbf{R})$ ADP- $\alpha$-S $(100 \mu \mathrm{M})$ or (S)-ADP- $\alpha$-S $(100 \mu \mathrm{M})$ (Figure le). Lineweaver-Burke analysis of these data gave an apparent dissociation constant $\left(K_{\mathrm{a}}\right)$ for ADP of 2.7 $\mu \mathrm{M}$, and $K_{\mathrm{i}}$ values for (R)-ADP- $\alpha$-S and (S)-ADP- $\alpha$ $\mathrm{S}$ of $32 \mu \mathrm{m}$ and $7.4 \mu \mathrm{m}$ respectively. (S)-ADP- $\alpha$-S was therefore about 4.5 times more potent than $(\mathbf{R})$ ADP- $\alpha-S$ (Figure 1f).

\section{Discussion}

These results show that the $\mathbf{R}_{\mathrm{P}}$ and $\mathbf{S}_{\mathrm{P}}$ diastereoisomers of $\mathrm{ADP}-\alpha-\mathrm{S}$ induce human platelet aggregation but do not inhibit $\mathrm{PGE}_{1}$-stimulated increases in levels of platelet cyclic AMP. The aggregation induced by each diastereoisomer was competitively inhibited by ATP, a known (Macfarlane \& Mills, 1975) ADP antagonist (Figure $1 \mathrm{~b}$ ). The $K_{\mathrm{i}}$ of $33 \mu \mathrm{m}$ obtained in each case compares well with our $K_{\mathrm{i}}$ for the inhibition by ATP of ADP $(25 \mu \mathrm{M})$ and with the published (Macfarlane \& Mills, 1975) value of $20 \mu \mathrm{m}$, indicating that the diastereoisomers cause aggregation by acting at the ADP receptor. The maximal rate of aggregation induced by each diastereoisomer was considerably less than that of ADP (Figure 1a), suggesting that they might have had a simultaneous inhibitory action. Evidence for this was provided by log dose-response curves for aggregation induced by ADP in the presence of each diastereoisomer. At low concentrations of ADP the agonist effect of each diastereoisomer dominated but at concentrations of ADP high enough to mask this agonist action, ADP had less aggregating effect in the presence of either diastereoisomer than in their absence (Figure 1c).

This inhibitory action of each diastereoisomer could have been due either to the appearance at high concentrations of a separate inhibitory effect not specific for ADP, or to a low efficacy at the ADP receptor. No inhibitory action was found when platelets were aggregated in the presence of either diastereoisomer by 11,9 -epoxymethano $\mathrm{PGH}_{2}$ (Figure 1d), which acts at a prostaglandin receptor (MacIntyre, Salzman \& Gordon, 1978), and our evidence therefore suggests that (R)-ADP- $\alpha$-S and (S)-ADP$\alpha$-S are partial agonists, each with an intrinsic activity of 0.75 , at the ADP receptor mediating aggregation of human platelets. This behaviour is similar to that of adenosine $5^{\prime}-\mathrm{O}-(2$-thiodiphosphate) (ADP- $\beta$-S), an ADP analogue in which a terminal $(\beta)$ phosphate oxygen is replaced by sulphur, which is also a partial agonist with an intrinsic activity of 0.75 as an aggregating agent (Cusack \& Hourani, 1981).

Unlike ADP, neither diastereoisomer of ADP- $\alpha$-S inhibited $\mathrm{PGE}_{1}$-stimulated adenylate cyclase, but each was a competitive inhibitor of the action of ADP (Figure $1 \mathrm{e}$ and $\mathrm{f}$ ). This is in contrast to the action on $\mathrm{PGE}_{1}$-stimulated adenylate cyclase of ADP- $\beta$-S, which is a partial agonist with an intrinsic activity here of 0.5 (Cusack \& Hourani, 1981).

In as much as (S)-ADP- $\alpha$-S was about 5 times more potent than (R)-ADP- $\alpha$-S both as an aggregating agent and as an inhibitor of the action of ADP on $\mathrm{PGE}_{1}$-stimulated adenylate cyclase, the platelet does show some stereoselectivity towards the 1-thiodiphosphate moiety of ADP- $\alpha$-S. (R)-ADP- $\alpha$-S and (S)-ADP- $\alpha$-S are the first ADP analogues found to induce aggregation of human platelets but to have no 

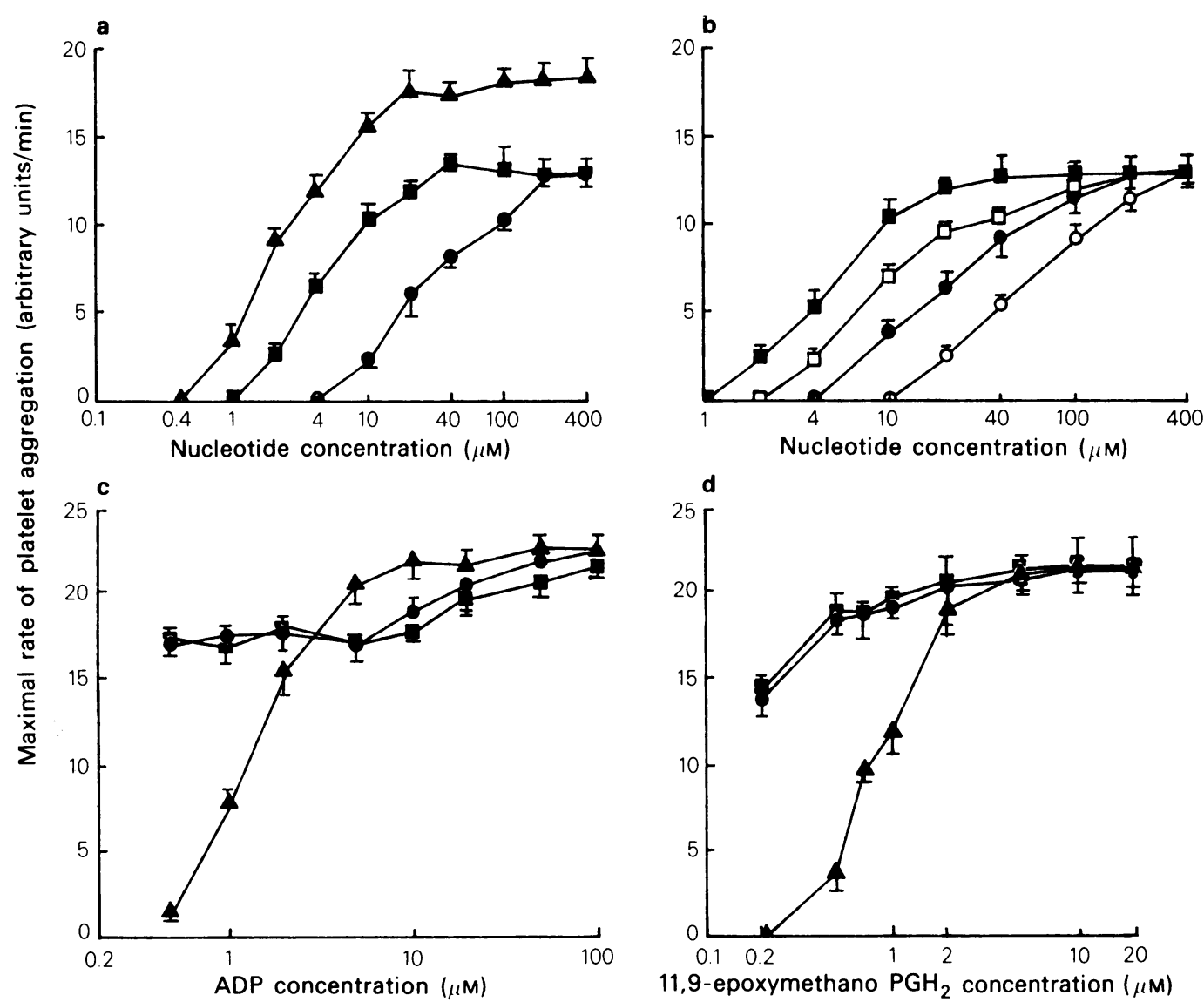

11,9-epoxymethano $\mathrm{PGH}_{2}$ concentration $(\mu \mathrm{M})$
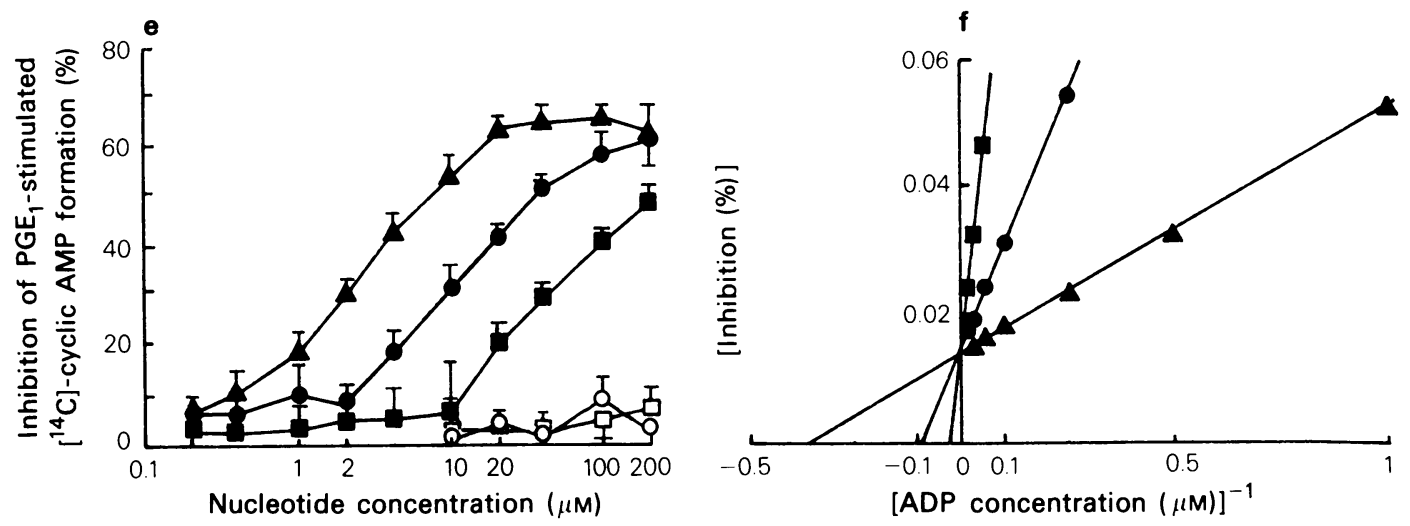

Figure 1 Effects of $\mathbf{R}_{\mathrm{P}}$ and $\mathbf{S}_{\mathrm{P}}$ diastereoisomers of ADP- $\alpha$-S on human platelets. (a) Comparison of aggregation induced by (R)-ADP- $\alpha-S(\mathbf{O}),(\mathbf{S})-A D P-\alpha-S(\square)$ and ADP $(\boldsymbol{\Delta})$ ). (b) Aggregation induced by (R)-ADP- $\alpha$-S in the absence $(\mathcal{O})$ and presence $(O)$ of ATP $(50 \mu \mathrm{M})$, and by (S)-ADP- $\alpha$-S in the absence $(\square)$ and presence ( $\square)$ of ATP $(50 \mu \mathrm{M})$. (c) Aggregation induced by ADP alone $(\boldsymbol{\Delta})$, or in the presence of (R)-ADP- $\alpha$-S $(200 \mu \mathrm{M})(\mathbf{O})$ or (S)-ADP- $\alpha-\mathrm{S}(200 \mu \mathrm{M})(\boldsymbol{\square})$. (d) Aggregation induced by 11,9-epoxymethano $\mathrm{PGH}_{2}$ alone ( $\left.\boldsymbol{\Delta}\right)$, or in the presence of (R)-ADP- $\alpha$-S $(200 \mu \mathrm{M})(\mathbf{O})$ or (S)-ADP- $\alpha$-S $(200 \mu \mathrm{M})(\boldsymbol{\sigma})$. (e) Inhibition of PGE 1 (1 $\mu \mathrm{M})$-stimulated formation of $\left[{ }^{1+} \mathrm{C}\right]$-cyclic AMP by ADP alone $(\boldsymbol{\Delta})$, or in the presence of $(\mathbf{R})-\mathrm{ADP}-\alpha-\mathrm{S}(100 \mu \mathrm{M})(\mathbf{O})$ or $(\mathrm{S})-\mathrm{ADP}-\alpha-\mathrm{S}(100 \mu \mathrm{M})$ (吕); (O) (R)-ADP- $\alpha$-S alone, (口) (S)-ADP- $\alpha$-S alone. All samples contained papaverine (2 mM). (f) Double reciprocal plot of data taken from (e). Lines were fitted by computer using least squares linear regression analysis. ( $\Delta$ ) ADP alone; (O) ADP and (R)-ADP- $\alpha$-S; ( $\mathbf{0}$ ) ADP and (S)-ADP- $\alpha$-S. All results are the mean of at least three determinations. Vertical bars show standard deviations. 
inhibitory action on $\mathrm{PGE}_{1}$-stimulated adenylate cyclase.

We thank the Medical Research Council for financial support (G 978/38/SA), the British Heart Foundation and

\section{References}

BURGERS, P.M.J. \& ECKSTEIN, F. (1978). Absolute configuration of the diastereoisomers of adenosine $5^{\prime}-\mathrm{O}-(1-$ thiotriphosphate): Consequences for the stereochemistry of polymerization by DNA-dependent RNA polymerase from Escherichia coli. Proc. natn. Acad. Sci. U.S.A., 75, 4798-4800.

CUSACK, N.J., HICKMAN, M.E. \& BORN, G.V.R. (1979). Effects of D- and L-enantiomers of adenosine, AMP and ADP and their 2-chloro- and 2-azido- analogues on human platelets Proc. R. Soc. Lond. B, 206, 139-144.

CUSACK, N.J. \& HOURANI, S.M.O. (1981). Partial agonist behaviour of adenosine 5'-O-(2-thiodiphosphate) on human platelets. Br. J. Pharmac., 73, 405-408.

ECKSTEIN, F. \& GOODY, R.S. (1976). Synthesis and properties of diastereoisomers of adenosine $5^{\prime}-(\mathrm{O}-1$ thiotriphosphate) and adenosine 5'-(O-2-thiotriphosphate). Biochemistry, 15, 1685-1691.

GAARDER, A., JONSEN, J., LALAND, S., HELLEM, A.J. \& OWREN, P.A. (1961). Adenosine diphosphate in red cells as a factor in the adhesiveness of human blood platelets. Nature, Lond., 192, 531-532.

HASLAM, R.J. (1973). Interactions of the pharmacological receptors of blood platelets with adenylate cyclase. Ser. Haemat., VI, 333-350.

HASLAM, R.J. \& ROSSON, G.M. (1975). Effects of adenosine on levels of adenosine cyclic $3^{\prime}, 5^{\prime}$-monophosphate in human blood platelets in relation to adenosine incorporation and platelet aggregation. Molec. Pharmac., $11,528-544$. the Fritz Thyssen Stiftung for equipment grants. the Vandervell Foundation for support for S.M.O.H. and Professor G.V.R. Born. F.R.C.P., F.R.S. for encouragement. Blood was taken by Dr. C. Fenn of this department. Correspondence to N.J.C. please.

MACFARLANE, D.E. \& MILLS, D.C.B. (1975). The effects of ATP on platelets: evidence against the central role of released ADP in primary aggregation. Blood, 46, 309-320.

MACFARLANE, D.E. \& MILLS, D.C.B. (1977). The number and nature of ADP receptors on human blood platelets determined with a photoaffinity label. Thrombos. Haemostas., 38, 241.

MACFARLANE, D.E., SRIVASTAVA, P.C. \& MILLS, D.C.B. (1979). 2-Methylthio-adenosine-5'-diphosphate (2MeSADP), a high affinity probe for ADP receptors on the human platelet. Thrombos. Haemostas., 42, 185.

MACINTYRE, D.E., SALZMAN, E.W. \& GORDON, J.L. (1978). Prostaglandin receptors on human platelets Structure-activity relationships of stimulatory prostaglandins. Biochem. J., 174, 921-929.

MICHAL. F. \& BORN, G.V.R. (1971). Effect of the rapid shape change of platelets on the transmission and scattering of light through plasma. Nature, Lond., 231. 220-222.

STAHL, K. -W., SCHLIMME, E. \& BOJANOWSKI, D. (1973). High-pressure liquid chromatography of modified purine mononucleotides and nucleosides. J. Chromatog., 83, 395-404.

(Received January 28, 1981 Revised February 23, 1981) 